KONSTAN
JURNAL FISIKA DAN PENDIDIKAN FISIKA
Volume 5, Nomor 2, Desember 2020
E-ISSN : 2460-9129 dan P-ISSN : 2460-9110
http://jurnalkonstan.ac.id/index.php/jurnal

\title{
PHYSICS COMPREHENSIVE CONTEXTUAL TEACHING MATERIAL UNTUK MENINGKATKAN KEMAMPUAN ARGUMENTASI
}

\author{
Muhammad Zaini ${ }^{1{ }^{*}}$, Nugroho Prasetya $\mathrm{Adi}^{2)}$, Lalu Usman Ali ${ }^{1)}$ \\ 1) Program Studi Tadris Fisika, Fakultas Tarbiyah dan Keguruan, Universitas Islam Negeri \\ Mataram, Jl. Pendidikan No. 35 Mataram, Indonesia, \\ 2) Universitas Sains Al-Qur'an, Jl. KH. Hasyim Asy'ari Km. 03, Kalibeber, Mojotengah, \\ Wonosobo, Jawa Tengah, Indonesia.
}

\begin{tabular}{l}
\hline Info Artikel \\
\hline Sejarah Artikel: \\
Diterima 30 Oktober 2020 \\
Disetujui 21 Desember 2020 \\
Dipublikasikan 30 \\
Desember 2020
\end{tabular}

Kata Kunci:

Contextual Teaching

Learning, Kemampuan

Argumentasi

\begin{abstract}
Contextual Teaching Learning (CTL) is learning based on contextual events in daily life. The development of teaching materials assisted by android applications in learning physics is a very necessary thing and needs to be carried out continuously. This research aims to produce android-assisted PhyCCTM teaching materials that can improve the ability of argumentation. This research is research and development. The Validator consist of four lecturers and seven physics teachers. Field trials are carried out in schools by applying the quasiexperimental method and using the control group pretest and posttest design. The trial was conducted by taking two classes as experimental and control classes. Improvement and differences in the results of students' argumentation abilities in the experimental and control groups were done by t-test. The research results obtained are android-assisted PhyCCTM teaching materials to improve the ability of argumentation worthy to be used with the category of "Good" and androidassisted PhyCCTM able to improve students' ability to argue with sig. (2-tailed) of 0,000. The conclusion obtained from this study is that Android-assisted PhyCCTM teaching materials developed are feasible to use and are able to improve students' ability to argue.
\end{abstract}

(C) 2020 Universitas Islam Negeri Mataram

* Corresponding Author: muhammadzaini@uinmataram.ac.id

Alamat korespodensi:

Gedung Pasca Sarjana Lantai 3 Kampus 2 UIN Mataram, Jl. Gajah Mada 100 Jempong Mataram, Indonesia

Email: jurnalkonstan@uinmataram.ac.id 


\section{PENDAHULUAN}

Pendidikan yang bermakna merupakan bekal setiap individu untuk menjalani kehidupan selanjutnya, tanpa pendidikan yang baik maka keterpurukan bisa saja melanda manusia Indonesia. Situasi seperti ini tentu saja harus dihindari dengan berbagai inovasi terkait peningkatan mutu pendidikan di Indonesia [1]. Pendidikan sebagai sarana belajar harus berkontribusi kuat dalam peningkatan SDM yang berkemampuan tinggi untuk menciptakan sesuatu yang baru, agar apa yang dihasilkan mampu meningkatkan kualitas hidup setiap manusia Indonesia.

Kemampuan yang tinggi dalam menciptakan sesuatu yang baru diperoleh dari pendidikan yang baik [2]. Prestasi pendidikan Indonesia secara umum belum memperlihatkan keberhasilan yang merata, sehingga mengakibatkan kemampuan siswa dalam belajar masih tergolong rendah dan sulit dalam memecahkan permasalahan-permasalahan di dalam kehidupan sehari-hari. Indonesia sangat membutuhkan inovasi dalam bidang IPTEK untuk mampu bersaing dengan negaranegara lain [3]. Peningkatan SDM yang lemah terutama dalam bidang pendidikan disebabkan oleh beberapa faktor, diantaranya adalah pembelajaran yang masih kurang efektif. Keefektifan pembelajaran akan terlihat dari adanya peningkatan kemampuan siswa setelah diajarkan suatu topik tertentu. Kenyataan ini harus disikapi dengan serius oleh seluruh lapisan masyarakat yang terkait dalam bidang pendidikan, jika tidak SDM Indonesia akan sulit bersaing dengan negara-negara maju yang ada di dunia [4-5].

Kualitas pendidikan Indonesia, khususnya dalam fisika memang belum sampai pada harapan semestinya. Fisika sebagai salah satu pilar pengembangan teknologi belum mampu menunjukkan hasil yang maksimal, terlihat dari berbagai inferior teknologi yang beredar di Indonesia adalah milik asing seperti jepang, Jerman, Amerika, dan lain-lain. Sumber daya alam (SDA) yang melimpah ternyata belum mampu juga dimanfaatkan sebagai sumber produksi kebutuhan lain, lagi-lagi disebabkan oleh teknologi yang tidak memadai. Penyediaan teknologi yang sangat minim harus diatasi melalui implementasi pembelajaran fisika yang bermutu, sehingga siswa memiliki kemampuan yang baik dalam berargumentasi untuk memecahkan setiap permasalahan fisika [6].

Kemampuan yang sangat dibutuhkan dalam pembelajaran abad 21 ini adalah hard skill dan soft skill. Paradigma pembelajaran abad 21 ini menekankan pada kemampuan siswa untuk berpikir kritis, mampu menghubungkan ilmu dengan dunia nyata, menguasai teknologi informasi, berkomunikasi dan berkolaborasi" [7-9].

Modernisasi tekhnologi selalu berkaitan dengan berbagai penemuan dalam berbagai bidang studi, salah satunya fisika. Ilmu fisika sebagai salah satu jalan dalam memperoleh temuan melalui suatu pemecahan masalah. Tujuan utama dalam fisika adalah kompeten dalam memecahkan masalah, salah satunya bagaimana mengargumentasikan konsep fisika dengan baik dan benar [10-12].

Faktor lain yang mempengaruhi kualitas pembelajaran fisika adalah bagaimana fisika itu diajarkan di dalam kelas. Pembelajaran fisika sebagian besar hanya diajarkan berdasarkan teori yang ada di buku, sehingga siswa sulit membayangkan fenomena fisis yang terjadi [13-15]. Dampak dari hal tersebut adalah rendahnya minat belajar fisika siswa, jika minat sudah tidak ada maka akan memberi pengaruh negatif terhadap hasil belajarnya. Kebutuhan setiap siswa adalah mendapatkan 
pemahaman yang baik dalam setiap materi yang disampaikan oleh guru. Pemahaman yang berharga datang dari pengalaman siswa yang berkaitan dengan fenomena fisis dalam kehidupan sehari-hari [16]. Salah satu pembelajaran dengan basis pengalaman adalah contextual teaching learning(CTL). Pembelajaran CTL erat kaitannya dengan konsep konstruktivisme yang menekankan pada hakikat pengetahuan mempengaruhi konsep dan proses pembelajaran. Belajar bukan hanya sekedar menghafal, namun mengonstruksi pengetahuan dari pengalaman dan interaksi.

CTL membentuk siswa menjadi lebih aktif dalam diskusi dan tanya-jawab terkait pemahaman yang diperoleh melalui pengalaman percobaan yang telah diperoleh. Rendahnya keterampilan dalam pembelajaran fisika disebabkan oleh pemahaman siswa yang tidak komprehehensif [17]. Fisika hendaknya diajarkan sesuai hakikatnya secara komprehensif agar memberikan keterampilan untuk mengamati, menganalisis, menemukan dan menciptakan.

Android dapat diimplementasikan dalam lingkungan fisika yang nyata. Aplikasi android dapat menggunakan lingkungan yang nyata sebagai sebuah pembelajaran untuk siswa. Sehingga melalui android, pembelajaran fisika yang berkaitan dengan gejala alam (kontekstual) dapat menjadi bahan pengajaran dikelas untuk memperoleh suatu pemahaman yang luas (komprehensif).

Berdasarkan paparan fakta di atas, kemampuan mengargumentasikan fisika sebagai tujuan utama, maka melalui physic contextual teaching material (PhyCCTM) berbantuan aplikasi android diharapkan mampu meningkatkan tujuan tersebut.

\section{METODE PENELITIAN}

Dalam penelitian pengembangan ini diterapkan model 4D dalam tahapan pengembangannya yang terdiri dari pendefinisian, perancangan, pengembangan, dan penyebaran. Bahan ajar yang dikembangkan ini sebelumnya diperiksa kevalidan dan kelayakannya oleh ahli yakni dosen dan guru. Setelah disimpulkan bahwa bahan ajar layak digunakan, maka dilanjutkan dengan uji coba lapangan ini digunakan pendekatan kuantitatif dengan metode penelitian kuasi eksperimen dengan menggunakan Control group Pre-test dan Post-test Design.

Tabel 1. Control group Pre-test dan Posttest Design.

\begin{tabular}{lcccc}
\hline $\begin{array}{l}\text { Kelas } \\
\text { Eksperimen }\end{array}$ & $\mathrm{T}_{1}$ & $\mathrm{X}$ & $\mathrm{T}_{2}$ & $\mathrm{~T}_{3}$ \\
\hline Kelas Kontrol & $\mathrm{T}_{2}$ & $\mathrm{Y}$ & $\mathrm{T}_{2}$ & $\mathrm{~T}_{3}$ \\
\hline
\end{tabular}

Berdasarkan Tabel 1, terdapat dua jenis kelompok yakni kelompok eksperimen dan kelompok kontrol. Sebelum diberikan perlakuan, terlebih dahulu kedua kelas diberikan pretest dengan tujuan untuk mengetahui kemampuan awal siswa. Setelah memperoleh hasil pretest, Kelompok eksperimen diberikan perlakukan menggunakan bahan ajar PhyCCTM berbantuan aplikasi android yang telah dikembangkan, sedangkan pada kelompok kontrol diberikan perlakukan sebagaimana pembelajaran sebelumnya menggunakan bahan ajar yang biasa digunakan. Setelah diberikan perlakuan pada kedua kelompok, maka kedua 
kelompok diberikan posttest guna mengetahui kemampuan akhir siswa. Apabila terdapat siswa yang memiliki nilai yang dibawah standard, maka akan diberikan pengayaan agar semua siswa tuntas dalam pembelajaran pada materi itu. Pada penelitian ini, materi yang diajarkan adalah materi impuls dan momentum. Partisipan dalam penelitian ini terdiri dari 36 siswa pada kelompok eksperimen dan 35 siswa pada kelompok kontrol.

Data yang diperoleh terdiri atas dua jenis yaitu data primer dan data sekunder. Data primer adalah data tentang kualitas kelayakan bahan ajar berbantuan aplikasi android sebagai produk hasil pengembangan. Data yang dikumpulkan berupa hasil penilaian ahli instrumen, ahli materi, ahli media, dan guru. Data tersebut meliputi skor penilaian dari aspek kelayakan isi, aspek kebahasaan, aspek penyajian, aspek kegrafikan, dan berupa komentar dan saran dari para ahli dan guru fisika. Data sekunder yang diperoleh adalah data yang diperoleh dari kegiatan pembelajaran.

Teknik pengumpulan data pada penelitian ini menggunakan teknik angket dan tes. Sedangkan, teknik analisis data untuk mengukur validitas menggunakan validitas aiken's V. Persamaan sebagai berikut.

$$
V=\frac{\sum n_{i}|i-r|}{N(t-1)}
$$

Hasil penilaian kelayakan dilakukan dengan melakukan perhitungan agar dapat disajikan secara kuantitatif. Langkah-langkahnya adalah memeriksa jawaban pada angket yang telah diisi oleh responden, mentabulasikan semua data yang diperoleh dari tahap validasi untuk semua komponen yang tersedia dalam instrument, menghitung skor rata-rata setiap komponen, dan skor yang diperoleh dianalisis dan dikonversi menjadi empat criteria seperti yang tersaji pada tabel berikut.

Tabel 2. Interval Skor

\begin{tabular}{ll}
\hline \multicolumn{1}{c}{ Interval Skor } & \multicolumn{1}{c}{ Kriteria } \\
\hline $\mathrm{M}_{\mathrm{i}}+1,5 \mathrm{SD}_{\mathrm{i}} \leq \bar{M} \leq \mathrm{M}_{\mathrm{i}}+3,0 \mathrm{SD}_{\mathrm{i}}$ & Sangat \\
\hline $\mathrm{M}_{\mathrm{i}}+0 \mathrm{SD}_{\mathrm{i}} \leq \bar{M} \leq \mathrm{M}_{\mathrm{i}}+1,5 \mathrm{SD}_{\mathrm{i}}$ & Baik \\
\hline $\mathrm{M}_{\mathrm{i}}-1,5 \mathrm{SD}_{\mathrm{i}} \leq \bar{M} \leq \mathrm{M}_{\mathrm{i}}+0 \mathrm{SD}_{\mathrm{i}}$ & Cukup \\
\hline $\mathrm{M}_{\mathrm{i}}-3,0 \mathrm{SD}_{\mathrm{i}} \leq \bar{M} \leq \mathrm{M}_{\mathrm{i}}-1,5 \mathrm{SD}_{\mathrm{i}}$ & Kurang \\
\hline
\end{tabular}

Data hasil tes diukur menggunakan Gain ternormalisasi. Persamaannya adalah sebagai berikut.

$$
<g>=\frac{<s_{f}>-<s_{i}>}{\text { nilaimaksimal }-<s_{i}>}
$$


Analisis peningkatan kemampuan argumentasi pada kelas eksperimen dan kelas kontrol menggunakan uji t dengan bantuan SPSS.

\section{HASIL DAN PEMBAHASAN}

Perangkat pembelajaran PhyCCTM yang dinilai oleh ahli adalah silabus, RPP, materi ajar, Aplikasi Android, dan soal. Perangkat pembelajaran dinilai menggunakan skala 4. Rata-rata skor penilaian dosen dapat dilihat pada Gambar 1.

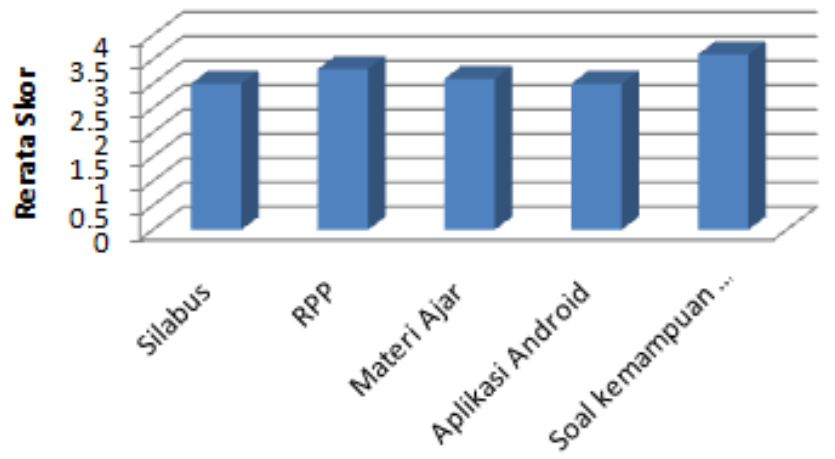

Gambar 1. Rerata Skor Penilaian Dosen

Berdasarkan Gambar 1, rata-rata skor penilaian dosen terhadap perangkat pembelajaran silabus sebesar 3,00 dengan kategori baik, rerata skor RPP sebesar 3,30 dengan kategori baik, rerata skor materi ajar sebesar 3,10 dengan kategori baik, rerata skor Aplikasi android sebesar 3,0 dengan kategori baik, dan rerata skor soal evaluasi kemampuan argumentasi sebesar 3,6 dengan kategori sangat baik. Selain memberikan penilaian, dosen ahli juga menyatakan bahwa perangkat pembelajaran berbasis android yang telah dikembangkan sudah dapat digunakan dalam proses pembelajaran fisika dengan catatan bahwa semua kekurangan dalam perangkat perlu diperbaiki terlebih dahulu sesuai dengan saran dan komentar yang diberikan.

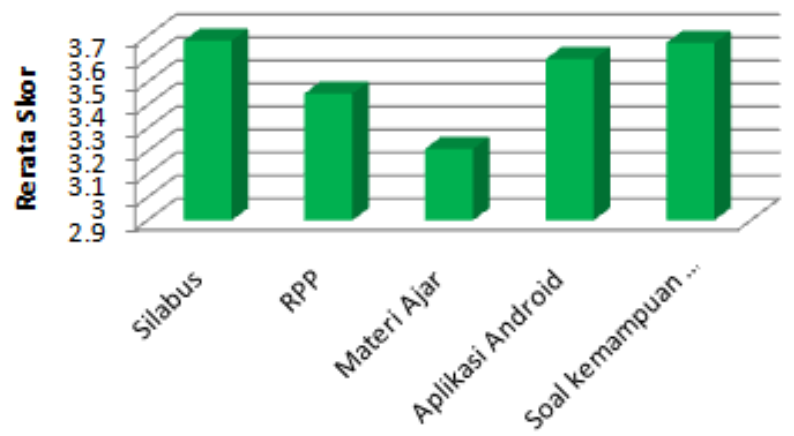

Gambar 2. Rerata Penilaian Guru

Perangkat pembelajaran yang dinilai oleh guru fisika pada masing-masing sekolah adalah silabus, RPP, materi ajar, Aplikasi android, dan soal. Data perolehan penilaian yang telah dilakukan oleh guru fisika dapat dilihat pada Gambar 2. 
Berdasarkan gambar 2, data yang telah diperoleh dari hasil penilaian guru fisika terhadap perangkat pembelajaran yang telah dikembangkan memiliki rerata skor pada silabus sebesar 3,68 dengan kategori sangat baik, rerata skor RPP sebesar 3,45 dengan kategori baik, rerata skor pada materi ajar sebesar 3,21 dengan kategori baik, rerata aplikasi android sebesar 3,60 dengan kategori sangat baik, dan rerata skor pada soal sebesar 3,67 dengan kategori sangat baik. Di samping memberikan penilaian terhadap perangkat pembelajaran, guru fisika juga menyatakan pendapatnya bahwa perangkat pembelajaran yang telah dikembangkan sudah bisa diterapkan dalam proses pembelajaran fisika dengan catatan memperbaiki kekurangan yang ada sesuai dengan saran dan komentar yang diberikan. Perangkat pembelajaran secara keseluruhan sudah memenuhi kategori yang baik dan sangat baik.

Analisis validitas, reliabilitas, dan deskripsi butir soal dilakukan melalui survey pendahuluan yang telah dilakukan pada penelitian tahap I. Data diperoleh melalui penyebaran tes soal kepada siswa dan digunakan untuk menentukan validitas dan reliabilitasnya menggunakan rasch model. Data yang telah diperoleh dapat dilihat pada tabel 2 dan tabel berikut.

Tabel 2. Summary of 12 Measured Item

\begin{tabular}{ccccccccc}
\hline & Total & Count & Measurs & Model & \multicolumn{2}{c}{ Infit } & \multicolumn{2}{c}{ Outfit } \\
\cline { 5 - 8 } & Scors & & & error & MNSQ & ZSTD & MNSQ & ZSTD \\
\hline Mean & 260,2 & 134,0 & 0,00 & 0,09 & 0,99 & $-0,3$ & 1,04 & 0,0 \\
\hline S.D. & 49,3 & 0,0 & 0,35 & 0,01 & 0,20 & 2,1 & 0,26 & 2,0 \\
\hline Max & 355,0 & 134,0 & 0,46 & 0,10 & 1,41 & 4,2 & 1,49 & 4,0 \\
\hline Min & 202,0 & 134,0 & $-0,64$ & 0,08 & 0,62 & $-4,8$ & 0,62 & $-3,8$ \\
\hline REAL & TRUE SD: 0,34 & SEPARATION: & ITEM RELIABILITY: \\
RMSE: 0,9 & \multicolumn{4}{c}{3,70} \\
\hline REAL & TRUE SD: 0,34 & SEPARATION: & \multicolumn{3}{c}{ ITEM RELIABILITY: } \\
RMSE: 0,9 & \multicolumn{4}{c}{3,84} \\
\hline
\end{tabular}

Berdasarkan tabel 2 diatas, dapat dilihat nilai alpha crownbach adalah 0,93 dan 0,94 yang berarti bahwa reliabilitas soal problem solving tergolong "Baik Sekali". Nilai INFIT MNSQ dan OUTFIT MNSQ adalah 0,99 dan -0,3, hal ini menunjukkan instrumen soal problem solving memiliki validitas yang cukup baik karena mendekati nilai ideal sebesar 1,00.

Tabel 3. Summary Of 134 Measured Person

\begin{tabular}{ccccccccc}
\hline & Total & Count & Measurs & Model & \multicolumn{2}{c}{ Infit } & \multicolumn{2}{c}{ Outfit } \\
\cline { 6 - 9 } & Scors & & & error & MNSQ & ZSTD & MNSQ & ZSTD \\
\hline Mean & 23,3 & 12,0 & $-0,55$ & 0,30 & 0,99 & 0,0 & 1,04 & $-0,1$ \\
\hline S.D. & 4,4 & 0,0 & 0,40 & 0,06 & 0,29 & 0,9 & 0,44 & 0,9 \\
\hline Max & 36.0 & 12,0 & 0,40 & 0,61 & 1,72 & 1,9 & 2,94 & 2,2 \\
\hline Min & 14,0 & 12,0 & $-1,82$ & 0,26 & 0,35 & $-2,3$ & 0,37 & $-2,2$ \\
\hline
\end{tabular}


Berdasarkan Tabel 3, dapat dilihat bahwa nilai INFIT MNSQ dan OUTFIT MNSQ pada person adalah 1,04 dan -0,1 yang menunjukkan bahwa validitas instrumen tergolong cukup baik. Gambar 3 memperlihatkan bagaimana kemampuan argumentasi siswa pada uji terbatas yang telah dilakukan.

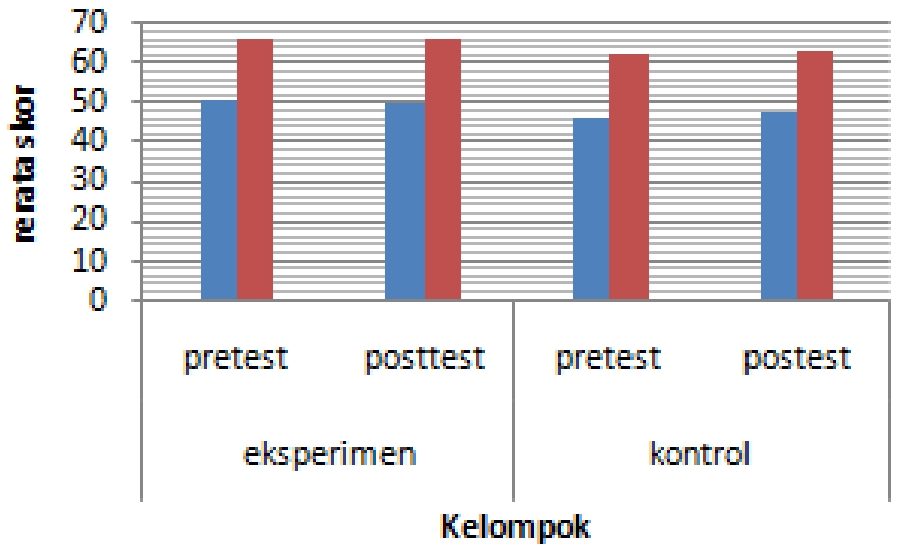

Gambar 3. Hasil Pretest dan Posttest

Berdasarkan gambar 3, diperoleh data rerata hasil pretest dan posttest sebesar 50,31 dan 64,47 dengan gain 0,27. Dari data pretest dan posttest, dapat dilihat bahwa nilai kemampuan argumentasi pada saat posttest lebih tinggi dari pada nilai dari hasil pretest yang telah dilakukan. Hasil ini menunjukkan adanya peningkatan kemampuan argumentasi siswa setelah diberikan perlakuan berupa pemberian physics comprehensive contextual teaching material yang telah dikembangkan.

\section{SIMPULAN DAN SARAN}

Dalam penelitian dan pengembangan ini diperoleh kesimpulan bahwa perangkat pembelajaran PhyCCTM berbasis android layak digunakan untuk meningkatkan kemampuan argumentasi siswa berdasarkan pada hasil uji kelayakan oleh dosen dan guru fisika yang tergolong dalam kategori baik dan sangat baik.

Berdasarkan hasil uji t yang telah dilakukan, nilai sig. (2-tailed) yang diperoleh sebesar 0,000. Nilai ini lebih kecil dari 0,005, yang berarti bahwa terdapat peningkatan nilai siswa setelah diajarkan menggunakan PhyCCTM berbasis android yang telah dikembangkan. Sehingga dapat disimpulkan bahwa penggunaan perangkat pembelajaran PhyCCTM berbasis android ampu meningkatkan kemampuan argumentasi siswa.

Setelah melakukan penelitian ini, peneliti menyarankan agar penelitian pengembangan terus berlanjut dengan mengangkat tema dari berbagai variabel yang lebih inovatif dan kreatif serta kedepannya mampu mewujudkan pendidikan yang bermutu dan berdaya saing. 


\section{UCAPAN TERIMA KASIH}

Terimakasih penulis ucapkan kepada seluruh pihak yang terlibat dalam penyusunan jurnal pendidikan fisika ini, semoga tulisan ini dapat bermanfaat untuk perbaikan selanjtunya

\section{DAFTAR PUSTAKA}

[1] Ogilvie, C. A. (2014). Changes in Students Problem Solving Strategies in a Course That Includes Context-Rich, Multifaceted Problems. Physics Education Research, 5 (2), 1-14.

[2] Fitri, L. A., Kurniawan, E. S., \& Ngazizah, N. (2012). Pengembangan Modul Fisika pada Pokok Bahasan Listrik Dinamis Berbasis Domain Pengetahuan Sains untuk Mengoptimalkan Minds-on Siswa SMA 2 Purworejo Kelas X Tahun Pelajaran 2012/2013. Radiasi, 3 (2), 19-23.

[3] Khusniati, M. 2012. Pendidikan Karakter melalui Pembelajaran IPA. Jurnal Pendidikan IPA, 2 (1), 204-210.

[4] Nugroho, P. A., \& Yulianto, R. A. (2019). Menumbuhkan Sikap Ilmiah (Kolaborasi, Keterbukaan Diri, dan Tanggung Jawab) melalui Pembelajaran Kontekstual. SPEKTRA, 2 (5), 140-148.

[5] Wahyuni, D E., \& Arief, A. (2015). Implementasi Pembelajaran Scientific Approach dengan Soal Higher Order Thinking Skills pada Materi Alat-alat Optik Kelas X SMA Nahdlatul Ulama' 1 Gresik. Jurnal Inovasi Pendidikan Fisika, 7 (3), 32-37.

[6] Ding, L., Reay, N., Lee, A., et al. (2015). Exploring The Role of Conceptual Scaffolding in Solving Synthesis Problems. Physical Review Special TopicsPhysics Education Research, 7 (2), 1-11.

[7] Maielfi, D., Ratnawulan, \& Usmeldi. (2012). Pengembangan Perangkat Pembelajaran Fisika dengan Pendekatan Contextual Teaching Learning Berbasis Iman dan Taqwa. Jurnal Penelitian Pembelajaran Fisika, 1 (1), 1-14.

[8] Lumbantoruan, A., \& Jannah, N. (2020). Deskripsi Sikap Siswa terhadap Fisika. SPEKTRA, 2 (5), 161-172.

[9] Yuliani, H., Sunarno, W., \& Suparmi. (2012). Pembelajaran Fisika dengan Pendekatan Keterampilan Proses dengan Metode Eksperimen dan Demonstrasi Ditinjau dari Sikap Ilmiah dan Kemampuan Analisis. Jurnal Inkuiri, 1 (2), 207216.

[10] Setiawan, A., Sutarto, \& Indrawati. (2012). Metode Praktikum dalam Pengantar Fisika SMA: Studi pada Konsep Besaran dan Satuan Tahun Ajaran 2012-2013. Program Studi Pendidikan Fisika FKIP Universitas Jember, 1 (1), 285-290.

[11] Perdana, R., Subiyantoro, C., \& Anggraini, L. (2013). Sikap dan Motivasi pada Mata Pelajaran Fisika. SPEKTRA, 2 (2), 178-188.

[12] Warimun, S. E. (2012). Penerapan Model Pembelajaram Problem Solving Fisika pada Pembelajaran Topik Optika pada Mahasiswa Pendidikan Fisika. Jurnal Exacta, 10 (2), 111-114.

[13] Brown, C. J. (2013). Translating Current Science Into Materials For Highe School Via a Scientist-Teacher Partnership. Jurnal of Science Teacher Education, 25 (3), 239-262. 
[14] Meltzer, D. E., \& Thornton, R. K. (2014). Active Learning Instruction in Physics. American Association of Physics Teacher, 5 (4), 478-496.

[15] Smith, B. P. (2013). Instructional Strategies in Family and Consumer Sciences: Implementing The Contextual Teaching and learning Pedagogical Model. Journal of Family \& Consumer Sciences Education, 28 (6), 23-28.

[16] Ampa, A. T., Basri, M., \& Andriani, A. A. (2013). The Development of Contextuall Learning Materials for the English Speaking Skills. International Journal of Education and Research, 1 (2), 1-10.

[17] Kitto, I. (2014). A Contextual General Systems Theory. Systems, 2 (4), 541565 . 